looking at LBP occurrence fever the past month in a sample of 633 subjects. The third was in an occupational setting addressing past history of LBP and included 201 individuals.

Results Among adults, prevalence of LBP at any given day was 13.1 (CI:11.0-14.2). Mean age is $41.8(\mathrm{SD}: 16.3)$ and $\mathrm{M} / \mathrm{F}$ ratio is 0.7 . A history of trauma was recorded by $13.2 \%(7.5-18.9)$ of LBP cases.

Among nurses, 54\% had experienced LBP over the past month. Handling patients was related to LBP by $60 \%$ (CI:5565 ) of nurses.

In an occupational setting, heavy workload is associated with higher frequency of LBP. $30.7 \%$ of those seeking medical care were offered a sick leave.

Conclusion At any given day,13.1\% (CI: 11.0-14.2) of adult population would report acute LBP. Workload is related to LBP occurrence. Sick leave is commonly prescribed for LBP.

\section{FRI0234 THE CORRELATION OF SPINAL CANAL DIMENSIONS AND CLINICAL FINDINGS IN LUMBAR SPINAL STENOSIS}

N Keser, OF Sendur, G Gurer, A Aydeniz. ADU Physical Medicine and Rehabilitation, ADU Medical School Hospital, Aydýn, Turkey

\subsection{6/annrheumdis-2001.538}

Background Spinal stenosis is narrowing of spinal canal, nerve root canal and intervertebral foramen under a critical value. Spinal degeneration is the most important reason for spinal stenosis. In most of the patient locomotor system examination is non-specific. Therefore detailed radiological examination should be done in order to make a definite diagnosis of spinal stenosis.

Objectives This study was carried out to investigate the correlation between lumbar spinal canal dimensions and clinical findings of patients who have suspected to have spinal stenosis.

Methods Forty patients ( 29 female, 11 male) were taken into this study. Detailed physical examination of locomotor system was done for each patient (lumbar range of motion, pain in lumbar extension, milligram test, muscle strength, deep tendon reflexes and sensory deficit).

CT scan of L3-L5 vertebrae level were done in order to measure A-P diameter of spinal canal, interpedicular distance, pedicular height.

Mann-Whitney U test was used for statistical analysis of data. Results We observed significant correlation between clinical findings of milligram test, pain in lumbar extansion, sensory deficit in lower extremities, deep tendon reflexes deficiency and some of CT scan results (A-P diameter and interpedicular distance of L4-L5) of patients who have spinal stenosis. There was no significant correlation between spinal stenosis and clinical findings of muscle strength deficit and lumbar ROM limitation

Conclusion We concluded that CT scan measurement and clinical findings of spinal stenosis correlate well. However soft tissues couldn't be evaluated properly and it is well known that these tissues may lead to spinal stenosis too. MRI is expensive and CT-myelography is not so easy to apply. Because of that CT is a useful technique when compared to others.

\section{REFERENCES}

1 Verbiest H. Lumbar spinal stenosis. In: Youmans JR, ed. Neurological surgery. Philadelphia: WB Saunders, 1990: 2805-55

2 Hall S, Lowthian PJ. Lumbar spinal stenosis. In: Klippel JH, Dieppe PA, eds. Rheumatology. St Louis: Mosby, 1998, 4.5.1-6

\section{FRI0235 ANALGESIC EFFICACY OF TRAMADOL/PIROXICAM COMBINATION: CLINICAL ASPECTS}

K Sekelj-Kauzlaric, B Matanovic, N Kauzlaric, R Cop, S Potrebica. Special Hospital for Medicine Rehabilitation, Hospital of Toplice, Toplice, Croatia, Outpatient Clinic for Rheumatology, FM\&R, Zagreb, Croatia

\subsection{6/annrheumdis-2001.539}

\section{Background}

Objectives To evaluate the efficacy and safety of combination analgesic tramadol/piroxicam for the treatment of low back pain. Methods This 2- week study took place in two REHA-Centres in Croatia. Patients took medication as needed for the treatment of acute low back pain and/or osteoarthritis pain. They were given $20 \mathrm{mg}$ of piroxicam in the morning and $50 \mathrm{mg}$ of tramadol every $12 \mathrm{~h}$ for 15 days. Patients reported maximum pain relief (VAS scale 0 to 10) and rated overall efficacy (scale $1=$ poor to $5=$ excellent) at the final visit. Adverse events (AEs) were monitored throughout the study.

Results A total of 70 patients from two REHA-Centres provided data. We present the analysis of age, sex and profession. Most of our patients $(61 \%)$ were employed. Our patients needed therapy for osteoarthritis pain (52\%), low back pain (40\%) and other (osteoporosis, RA, SA) 8\%. After 15 days combination tramadol/ piroxicam provided pain relief (range 2,5 ? 3,5). Overall efficacy of combination was rated $35 \%$ ?very good? or ?excellent? by $20 \%$, ?good? by $35 \%$ and ?poor? by $10 \%$ only. There were no serious or unexpected AEs. The most common AEs were: nausea $20 \%$, constipation $18 \%$, headache $16 \%$, dizziness $12 \%$ and somnolence $8 \%$.

Conclusion This study demonstrated that the combination analgesic tramadol/piroxicam is effective and well tolerated in patients with low back pain and/or ostheoarthritis.

\section{FRI0236 THE EFFECTS OF LOW-ENERGY LASER AND EXERCISE THERAPY IN PATIENTS WITH CHRONIC LOW BACK PAIN: A DOUBLE-BLIND CONTROLLED TRIAL}

M Karakoç, A Gür, K Nas, R Çevik, AJ Saraç, F Erdoðan, M Karakoç (Çelik). Physical Medicine and Rehabilitation, Dicle University, Diyarbakyr, Turkey

10.1136/annrheumdis-2001.540

Background Low back pain is a ubiquitous health, problem and leads to majör problems. Low-energy laser biostimulation can be used to treat low back pain in last years.

Objectives The aim of this double-blind controlled clinical study is to evaluate the effectiveness laser and combined exercise + laser in patients with chronic low back pain.

Methods Forty patients with chronic low back pain randomly divided into two groups of 20 patients. 20 patients in the first group received low-energy laser + exercise treatment, other group received low-energy laser treatment alone. The parameters such as pain and muscle strength were assessed in all patients pretreatment and posttreatment. Pain measurement was done using the visual anologue scale. Muscle strength measurement (m. rectus abdominus, oblicus, hip abductors, hip adductors, extensors and internal rotators, knee flexors and extansors, foot flexors and extansors, and dorsal extansors) was done using the manual muscle strength testing.

Results Both groups demonstrated significant improvements visual analogue scale and rectus abdominus, hip adductors and abductors in posttreatment $(\mathrm{p}<0.05)$, but no relative advantage was found for either group ( $p>0.05)$. 